\title{
Particle size dependent deposition and pulmonary inflammation after short-term inhalation of silver nanoparticles
}

Hedwig M Braakhuis ${ }^{1,2^{*}}$, Ilse Gosens², Petra Krystek ${ }^{3}$, John AF Boere ${ }^{2}$, Flemming R Cassee ${ }^{2,4}$, Paul HB Fokkens ${ }^{2}$, Jan Andries Post ${ }^{5}$, Henk van Loveren ${ }^{1,2}$ and Margriet VDZ Park ${ }^{2}$

\begin{abstract}
Background: Although silver nanoparticles are currently used in more than 400 consumer products, it is not clear to what extent they induce adverse effects after inhalation during production and use. In this study, we determined the lung burden, tissue distribution, and the induction and recovery of adverse effects after short-term inhalation exposure to $15 \mathrm{~nm}$ and $410 \mathrm{~nm}$ silver nanoparticles.

Methods: Rats were nose-only exposed to clean air, $15 \mathrm{~nm}$ silver nanoparticles $\left(179 \mathrm{\mu g} / \mathrm{m}^{3}\right)$ or $410 \mathrm{~nm}$ silver particles $\left(167 \mu \mathrm{g} / \mathrm{m}^{3}\right) 6$ hours per day, for four consecutive days. Tissue distribution and the induction of pulmonary toxicity were determined at 24 hours and 7 days after exposure and compared with the internal alveolar dose. Presence of silver nanoparticles in lung cells was visualized by transmission electron microscopy (TEM).

Results: Exposure to $15 \mathrm{~nm}$ silver nanoparticles induced moderate pulmonary toxicity compared to the controls, indicated by a 175 -fold increased influx of neutrophils in the lungs, a doubling of cellular damage markers in the lungs, a 5-fold increase in pro-inflammatory cytokines, and a 1.5-fold increase in total glutathione at 24 hours after exposure. All the observed effects disappeared at 7 days after exposure. No effects were observed after exposure to $410 \mathrm{~nm}$ silver particles. The internal alveolar mass dose of the $15 \mathrm{~nm}$ nanoparticles was 3.5 times higher compared to the $410 \mathrm{~nm}$ particles, which equals to a 66,000 times higher particle number. TEM analysis revealed $15 \mathrm{~nm}$ nanoparticles in vesicles and nuclei of lung cells, which were decreased in size to $<5 \mathrm{~nm}$ at 24 hours after exposure. This demonstrates substantial dissolution of the silver nanoparticles.
\end{abstract}

Conclusion: The results show a clear size-dependent effect after inhalation of similar mass concentrations of $15 \mathrm{~nm}$ and $410 \mathrm{~nm}$ silver (nano)particles. This can be partially explained by the difference in the internal alveolar dose between the $15 \mathrm{~nm}$ and $410 \mathrm{~nm}$ silver (nano)particles as well as by a difference in the release rate of silver ions.

Keywords: Nanoparticles, Inhalation exposure, Pulmonary toxicity, Cellular uptake, Dissolution

\section{Background}

Nanomaterials are used in a rapidly increasing number of products including consumer products [1]. However, there are concerns these nanomaterials might introduce health risks upon occupational and consumer exposure. Although many nanomaterials are produced, handled and present in fluids, aerosolization may occur during

\footnotetext{
* Correspondence: hedwig.braakhuis@rivm.nl

'Department of Toxicogenomics, Maastricht University, PO Box 616,

Maastricht 6200, MD, the Netherlands

${ }^{2}$ National Institute for Public Health and the Environment (RIVM), PO Box 1, Bilthoven 3720, BA, the Netherlands

Full list of author information is available at the end of the article
}

energetic processes, such as vortexing, weighing, sonication, mixing and blending [2]. In addition, nanomaterials may be released from their matrix during its use. Therefore, inhalation is considered a relevant route of exposure [2,3]. Currently, silver nanoparticles are the most common nanoparticles mentioned in product descriptions. According to the Nanotechnology Consumer Products Inventory, silver nanoparticles are currently claimed to be used in more than 400 consumer products [1]. Silver nanoparticles have antimicrobial activity and are used in food packaging material, food supplements, odour-preventing textiles, cosmetics, kitchen utensils, 
toys, electronics, wound dressings, and room sprays $[1,4]$. Silver (nano)particles and released ions exert antimicrobial properties by binding to sulphur- and phosphorouscontaining biomolecules such as proteins and DNA, thereby potentially also causing damage to mammalian cells [5-9]. Besides worker exposure, the extensive use of silver nanoparticles in products might also lead to consumer exposure by inhalation of the silver nanoparticles that are used in spray applications. Although silver nanoparticles are currently claimed to be used in many products, it is not clear to what extend they induce adverse effects after inhalation during production and use.

Silver nanoparticles have been studied in several in vivo inhalation studies showing diverse outcomes. Some studies showed no induction of adverse effects $[10,11]$, while other studies reported adverse effects varying from a minimal inflammatory response to the presence of inflammatory lesions in the lungs [12-15]. Regarding the tissue distribution of the silver nanoparticles, some studies report a dose-dependent increase in the silver concentration in the lungs and in the liver $[11,13,15]$. Two of these studies report a rather high amount of silver detected in the brain and the olfactory bulb $[11,15]$, causing concerns that silver nanoparticles might induce toxicity in the brain.

The before mentioned inhalation studies show that silver nanoparticles can induce pulmonary inflammation and can decrease lung function, depending on the exposure time and dosage [10-15]. However, all of these studies focused on a single particle size. The previous studies did not take particle size and surface area into account as explaining variable, whereas these affect the internal dose and the interaction probability with cells. For particles to induce pulmonary inflammation, they must deposit in the alveolar region. The deposition of (nano)particles depends mostly on their (agglomerate) size. Nanoparticles with a primary or agglomerate particle size between 10 and $100 \mathrm{~nm}$ will deposit more efficiently in the alveolar region compared to particles with an agglomerate particle size between 0.1 and $1 \mu \mathrm{m}$ [16-20]. At a similar mass based exposure dose, particles of different sizes will have a different deposition pattern in the lungs, and the deposited dose in the alveoli ultimately determines the extent of the pulmonary toxic effects. The previous studies did not link the deposited dose in the alveoli to the observed effects [10-15].

Until now, the formulation in which silver nanoparticles induce toxicity remains unclear. The effects might be caused by the silver nanoparticles itself, the released silver ions, or a combination of both. Next to this, it remains unclear to what extend the geometric size of silver particles affect the induction of pulmonary inflammation. Since particle size is the most important particle characteristic that determines the deposited dose in the lungs and is of influence on the dissolution rate of silver nanoparticles, the aim of this study is to investigate the influence of particle size on pulmonary toxicity of silver nanoparticles. We hypothesize that small silver nanoparticles will induce more prominent pulmonary toxicity compared to larger silver particles because of the larger deposited dose in the alveoli and the higher dissolution rate. In the present study, we tested the effects of a similar mass exposure concentration of $15 \mathrm{~nm}$ and $410 \mathrm{~nm}$ silver (nano)particles after short-term nose-only inhalation exposure. The total lung burden was measured and used together with the exposure measurements as an input for the multiple path particle dosimetry (MPPD) model to estimate the alveolar dose. Transmission electron microscopy (TEM) was used to localize silver particles in the lung tissue and tissue distribution was measured to determine any differences in the kinetics of the silver particles. To determine the toxicity induced by $15 \mathrm{~nm}$ and $410 \mathrm{~nm}$ silver (nano)particles, body weight, total blood cell counts, inflammatory and cell damage markers in the bronchoalveolar lavage fluid (BALF) and histology of the lungs were analysed. All endpoints were determined at 24 hours and 7 days after the last exposure to investigate the possible recovery of adverse effects.

\section{Results}

\section{Nanoparticle characteristics}

The particle characteristics are summarized in Table 1 and shown in Additional file 1: Figure S1. The silver nanoparticles had a count median diameter of $15 \mathrm{~nm}$ (Figure 1) and the exposed dosage was $179 \mu \mathrm{g} / \mathrm{m}^{3}$ air. For the larger silver particles, the $200 \mathrm{~nm}$ primary silver particles agglomerated to a count median diameter of $410 \mathrm{~nm}$ (Figure 1) and the exposed dosage was $167 \mu \mathrm{g} / \mathrm{m}^{3}$ air. While the mass dosage was similar for both particle groups, the particle number dosage was $3.8 \times 10^{6}$ particles per $\mathrm{cm}^{3}$ for the $15 \mathrm{~nm}$ nanoparticles and $2.0 \times 10^{4}$ particles per $\mathrm{cm}^{3}$ for the $410 \mathrm{~nm}$ particles.

\section{Experimental design}

Since male rats showed more sensitivity towards induction of pulmonary inflammation compared to female rats after 90 days inhalation exposure [13,14], we chose to expose male rats. The rats were nose-only exposed for 6 hours per day, 4 consecutive days to fresh air, $15 \mathrm{~nm}$ silver nanoparticles or $410 \mathrm{~nm}$ silver particles, 12 rats per exposure group. Of each exposure group, 6 rats were sacrificed 24 hours after exposure and the other 6 rats were sacrificed 7 days after exposure.

\section{Quantification of silver in tissues by high resolution} inductively coupled plasma mass spectrometry (HR-ICP-MS) The presence of silver was measured with HR-ICP-MS in the lungs, liver, spleen, kidneys, brain, testis and lungassociated lymph nodes. Of these tissues, silver was 
Table 1 Nanoparticle characteristics

\begin{tabular}{llll}
\hline Agglomerate size $[\mathrm{nm}]$ & Mass $\left[\boldsymbol{\mu g} / \mathbf{m}^{\mathbf{3}}\right]$ & Particle number $\left[\# / \mathbf{c m}^{\mathbf{3}}\right]$ & Surface $\mathbf{a r e a}^{[}\left[\mathrm{nm}^{2} / \mathrm{cm}^{\mathbf{3}}\right]$ \\
\hline $15.3(1.26)$ & $179(107-252)$ & $3.8 \times 10^{6}(2.6-5.0)$ & $6.72 \times 10^{9}(3.97-9.49)$ \\
$410(1.43)$ & $167(147-187)$ & $2.0 \times 10^{4}(0.43-3.7)$ & $2.33 \times 10^{8}(0.28-2.61)$ \\
\hline
\end{tabular}

Particle size is given as count median diameter (CMD) with the geometric standard deviation (GSD). Mass, particle number and surface area shown as mean with a $95 \%$ confidence interval.

detected in the lungs and liver (Figure 2). At 24 hours after exposure, the lungs of the rats exposed to $15 \mathrm{~nm}$ nanoparticles contained $3.4 \mathrm{\mu g}$ silver per gram lung, whereas the lungs of the rats exposed to $410 \mathrm{~nm}$ particles contained $6.0 \mu \mathrm{g}$ silver per gram lung. This equals a total lung deposit (TLD) of $5.5 \mu \mathrm{g}$ of the $15 \mathrm{~nm}$ and $8.5 \mu \mathrm{g}$ of the $410 \mathrm{~nm}$ silver particles, respectively. Because the silver nanoparticles are spherical, we could use these measurements to estimate the number of silver nanoparticles deposited in the lungs. A total lung capacity (TLC) of $13.7 \mathrm{ml}$ [16] was used that results in $2.0 \times 10^{7}$ particles per $\mathrm{mm}^{3}$ of $15 \mathrm{~nm}$ nanoparticles and $1.6 \times 10^{3}$ particles per $\mathrm{mm}^{3}$ of $410 \mathrm{~nm}$ particles in the lungs. In the lung-associated lymph nodes, silver could be detected in one animal exposed to $15 \mathrm{~nm}$ silver nanoparticles. In the other animals, the level of silver in the lymph nodes was below the detection limit. In addition, the level of silver in the other tested tissues (spleen, kidneys, testis, brain) was below the detection limit of $0.01 \mu \mathrm{g} / \mathrm{g}$ tissue. At 7 days after exposure, the silver content in the lungs decreased to $1.3 \mu \mathrm{g} / \mathrm{g}$ tissue $(2.1 \mu \mathrm{g}$ TLD) for the rats exposed to $15 \mathrm{~nm}$ silver nanoparticles and $3.9 \mu \mathrm{g} / \mathrm{g}$ tissue $(5.9 \mu \mathrm{g}$ TLD) for the rats exposed to $410 \mathrm{~nm}$ silver particles. In the liver, silver was detected in the rats exposed to $15 \mathrm{~nm}$ silver nanoparticles at a level of $0.06 \mu \mathrm{g} / \mathrm{g}$ tissue $(0.53 \mu \mathrm{g}$ total $)$ at 24 hours after exposure and $0.01 \mu \mathrm{g} / \mathrm{g}$ tissue $(0.095 \mu \mathrm{g}$ total $)$ at 7 days after exposure, indicating removal of silver. No silver was detected in the liver of rats exposed to $410 \mathrm{~nm}$ silver particles at either time points.

\section{Estimated deposited dose in lungs using Multiple Path Particle Dosimetry Model (MPPD model)}

According to the MPPD model, the total deposited fraction in the lungs is similar for both particle sizes [16] at 0.69 for the $15 \mathrm{~nm}$ nanoparticles, and 0.67 for the $410 \mathrm{~nm}$ particles. However, according to our HR-ICPMS measurements, the TLD was $5.5 \mu \mathrm{g}$ for the $15 \mathrm{~nm}$ nanoparticles and $8.5 \mu \mathrm{g}$ for the $410 \mathrm{~nm}$ particles at 24 hours after exposure. The lower silver content in the lungs of the animals exposed to $15 \mathrm{~nm}$ particles might be explained by clearance of silver in the time between the end of the exposure and the sacrifice and after each day of exposure. The deposition in the alveoli differs between the two particle sizes: the deposited fraction in the alveoli is 0.27 for the $15 \mathrm{~nm}$ nanoparticles and 0.048 for the $410 \mathrm{~nm}$ particles [16]. Based on the HR-ICP-MS results, we estimated the deposited mass in the alveolar region was $2.1 \mu \mathrm{g}$ for the $15 \mathrm{~nm}$ nanoparticles and $0.6 \mu \mathrm{g}$ for the $410 \mathrm{~nm}$ particles at 24 hours after exposure, which equals $7.9 \times 10^{6}$ particles per $\mathrm{mm}^{3}$ for the $15 \mathrm{~nm}$ nanoparticles and 118 particles per $\mathrm{mm}^{3}$ for the $410 \mathrm{~nm}$ particles. Based on mass, the deposited dose in the alveoli was 3.5 times higher in the animals exposed to $15 \mathrm{~nm}$ silver nanoparticles compared to the animals exposed to $410 \mathrm{~nm}$ silver particles at 24 hours after
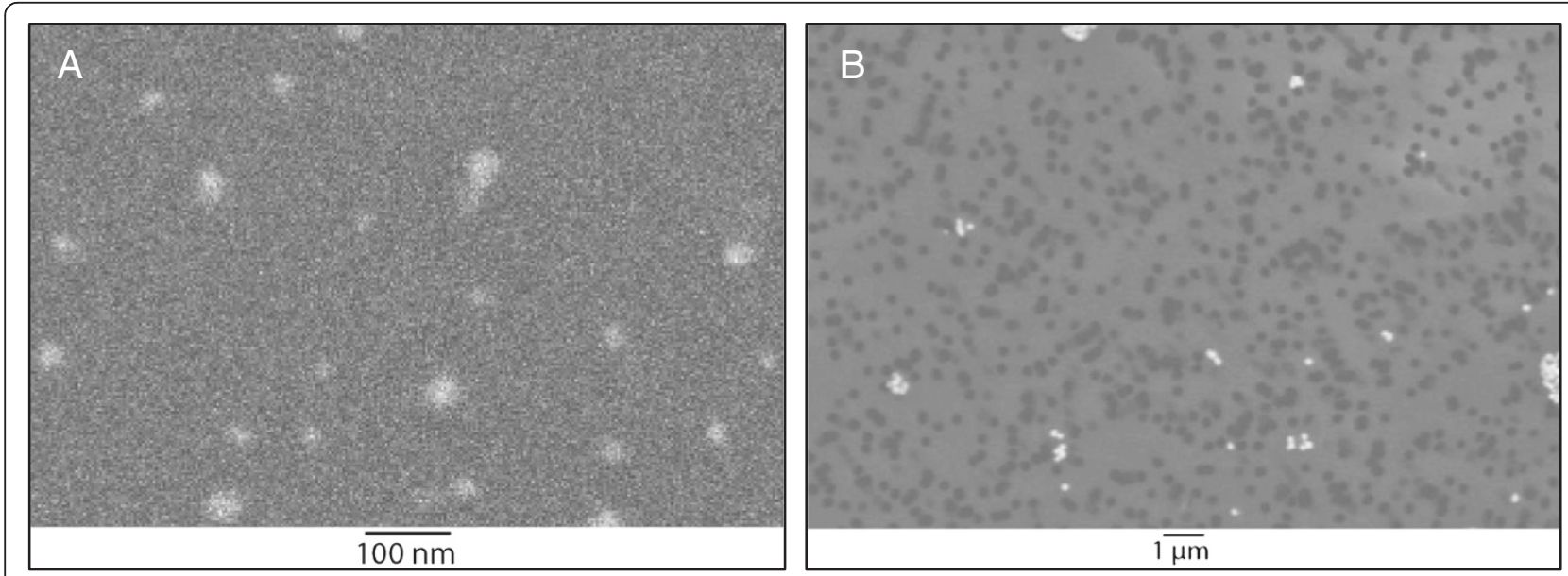

Figure 1 Scanning electron microscopy (SEM) pictures of the $15 \mathrm{~nm}$ silver nanoparticles (A) and the $410 \mathrm{~nm}$ silver particles (B) captured on polycarbonate filters with $0.22 \mu \mathrm{m}$ pores (Pictures are made in back-scatter mode). 


\section{Ag in lung and liver $(\mu \mathrm{g} / \mathrm{g})$}

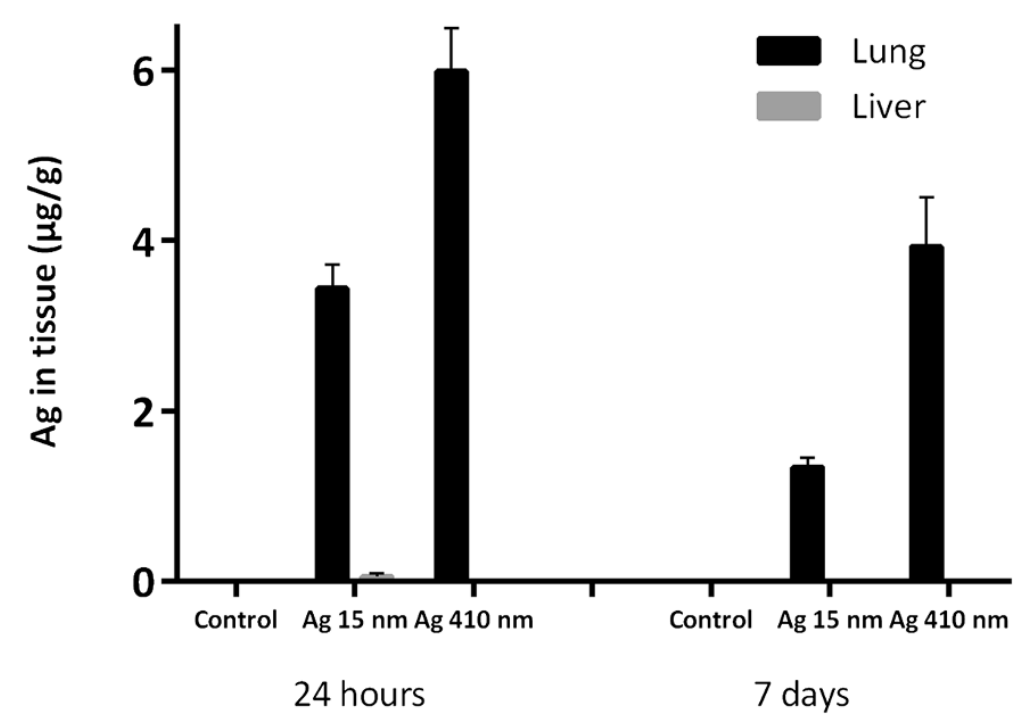

Figure $\mathbf{2}$ Amount of silver detected in the lungs and liver by HR-ICP-MS at $\mathbf{2 4}$ hours and $\mathbf{7}$ days after exposure. In the liver, silver could be detected in the animals exposed to $15 \mathrm{~nm}$ silver nanoparticles and not in the animals exposed to $410 \mathrm{~nm}$ silver particles. For both particle sizes, the amount of silver in the lungs at 7 days after exposure was significantly lower compared to 24 hours after exposure.

exposure. Based on particle number, the deposited dose in the alveoli was 66,000 times higher for the $15 \mathrm{~nm}$ compared to the $410 \mathrm{~nm}$ particle group.

\section{Electron microscopy of the lung}

As reported above, the estimated number of silver particles in the alveoli was $7.8 \times 10^{6}$ particles per $\mathrm{mm}^{3}$ for the $15 \mathrm{~nm}$ nanoparticles and 118 particles per $\mathrm{mm}^{3}$ for the $410 \mathrm{~nm}$ particles. The ultrathin TEM coupes are $70 \mathrm{~nm}$ thick; therefore, the expected number of particles per $\mathrm{mm}^{2}$ is 8 for the $410 \mathrm{~nm}$ particles, which may be too few to be detected. In contrast, for the $15 \mathrm{~nm}$ nanoparticles, the expected number is much higher: $5.5 \times 10^{5}$ nanoparticles per $\mathrm{mm}^{2}$. Despite of this relatively high number neither 15 nor $410 \mathrm{~nm}$ silver particles could be detected in TEM section of the in epon embedded lung tissue.

Dissolution of silver nanoparticles is known to occur and will clearly result in a decrease in the size of the silver nanoparticles. Silver nanoparticles below $5 \mathrm{~nm}$ are difficult to detect in a biological sample by EM. Therefore, we employed the silver enhancement technique, a well-known approach to detect for instance $1 \mathrm{~nm}$ gold particles, normally not detectable in a biological sample by TEM. Silver enhancement also intensifies the EM signal of the silver nanoparticles by homogenous deposition of metallic silver on the particles surface, thereby increasing the particle size of the silver nanoparticles in the processed tissue. After silver enhancement on grids containing ultrathin lung sections, electron dense structures were detected by TEM in the lungs of the animals exposed to $15 \mathrm{~nm}$ silver nanoparticles (Figure 3), whereas they were almost absent in ultrathin lung sections of control animals. Two different grids containing ultrathin lung sections of control animals and three different grids containing ultrathin lung sections of animals exposed to $15 \mathrm{~nm}$ silver nanoparticles were examined for the presence of silver nanoparticles; at least 50 cell profiles per ultrathin section were examined. After silver enhancement, in the lung sections of the control animals silver dots were detected in $2 \%$ of the examined cells, whereas in the lung sections from the animals exposed to $15 \mathrm{~nm}$ silver nanoparticles silver dots were detected in $56 \%$ of the examined cells. The silver nanoparticles were both present in alveolar macrophages and lung epithelial cells (Figure 3). The nanoparticles were located mostly in vesicle-like structures and in the nucleus (Figure 3). However, in some cells the silver dots seemed randomly spread. The size of these deposits after silver enhancement was about 15 $20 \mathrm{~nm}$. This indicates that the original particle size of the silver nanoparticles in the lung tissue, without deposition of metallic silver, was smaller than $5 \mathrm{~nm}$ (P. van de Plas, Aurion, Wageningen, the Netherlands; personal communication).

\section{Clinical examinations}

Exposure to silver nanoparticles of $15 \mathrm{~nm}$ and silver particles of $410 \mathrm{~nm}$ did not induce any premature mortality. There were no effects on animal attitude, fur, activity 

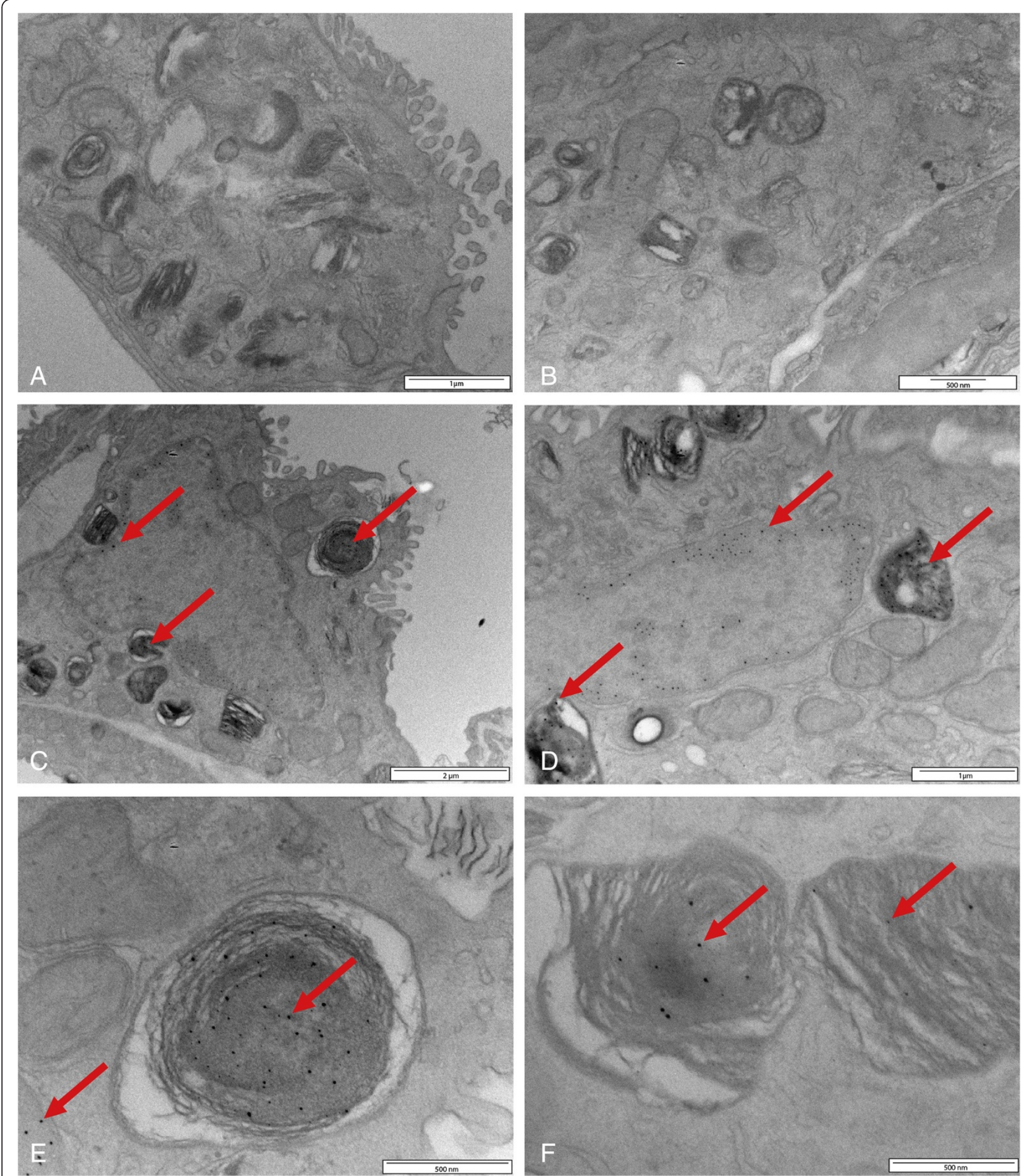

Figure 3 TEM pictures of lung tissue of rats exposed to clean air (A and B) or $15 \mathrm{~nm}$ silver nanoparticles (C, D, E and F), afterwards followed by silver enhancement. The pictures show the presence of silver nanoparticles in the nucleus, lamellar bodies and lysosomes of lung cells (indicated by the red arrows) at 24 hours after exposure.

pattern, food and water consumption and faeces and urine production, and no effects on body weights and organ weights throughout the study (Table 2).

\section{Hematology}

In the blood, the total amount of white blood cells and the amount of neutrophils and lymphocytes were all 
Table 2 Animal weights given in grams

\begin{tabular}{lllll}
\hline Group & Arrival & Start of exposure & 24 hours after exposure & $\mathbf{7}$ days after exposure \\
\hline Control & $187(178-197)$ & $235(218-253)$ & $232(220-243)$ & $250(237-263)$ \\
$15 \mathrm{~nm} \mathrm{Ag}$ & $188(179-197)$ & $237(228-245)$ & $231(222-240)$ & $248(243-253)$ \\
$410 \mathrm{~nm} \mathrm{Ag}$ & $187(177-197)$ & $240(228-253)$ & $234(221-247)$ & $243(229-258)$ \\
\hline
\end{tabular}

Data shown as mean with a $95 \%$ confidence interval.

increased in the group exposed to the $15 \mathrm{~nm}$ silver nanoparticles compared to the other groups at 24 hours after exposure (Figure 4). However, the differences were not statistically significant. At 7 days after exposure, there was no increase in any of the measured blood cells. There were no increases in inflammatory blood cells in the group exposed to $410 \mathrm{~nm}$ silver particles at both time points. The level of Fibrinogen in the plasma did not differ between the controls and the exposed groups at both time points (data not shown).

\section{Histopathology}

The histopathology analysis showed no differences between the groups. No lesions were observed in any of the lungs (results not shown).

\section{Total cell counts and differential cell counts in the bronchoalveolar lavage fluid (BALF)}

The cell counts in the bronchoalveolar lavage fluid (BALF) are shown in Figure 5. The total cell number was increased 24 hours after exposure to $15 \mathrm{~nm}$ silver nanoparticles compared to control $(p=0.063)$ and significantly increased compared to the group exposed to $410 \mathrm{~nm}$ silver particles $(p<0.05)$. The increased cell number is caused by a neutrophil influx (Figure 6). 24 hours after exposure, there was an average of $3.95 \times 10^{5}$ neutrophils per $\mathrm{ml}$ cell pellet in the group exposed to $15 \mathrm{~nm}$ silver nanoparticles compared to $2.3 \times 10^{3}$ neutrophils per $\mathrm{ml}$ pellet in the controls $(p<0.01)$ and $2.1 \times 10^{3}$ neutrophils per $\mathrm{ml}$ pellet in the $410 \mathrm{~nm}$ silver particles exposed animals $(p<0.01)$. In addition, the number of lymphocytes in the BALF was increased after exposure to $15 \mathrm{~nm}$ silver nanoparticles $(p<0.05$ compared to control, $p<0.05$ compared to $410 \mathrm{~nm}$ silver). The number of monocytes in the BALF 24 hours after exposure was also increased: 3300 monocytes per $\mathrm{ml}$ pellet in the group exposed to $15 \mathrm{~nm}$ silver nanoparticles compared to 150 in the controls and 0 in the group exposed to $410 \mathrm{~nm}$ silver particles ( $\mathrm{p}<0.01$ and $\mathrm{p}<0.001)$. Remarkably, the number of macrophages in the BALF was decreased 24 hours after exposure to $15 \mathrm{~nm}$ silver nanoparticles compared to control, although not statistically significant. There were no differences between the groups in number of multi-nuclei macrophages. There were no eosinophils detected in any of the exposed groups 24 hours after exposure.

The cell counts in the BALF at 7 days after exposure were completely different from those at 24 hours after exposure. At 7 days after exposure, most observed effects disappeared. There were no differences in the number of lymphocytes, macrophages and monocytes between the exposure groups. There was a slight decrease in the number of neutrophils in the BALF of rats exposed to $15 \mathrm{~nm}$ silver nanoparticles compared to both control and $410 \mathrm{~nm}$ silver particles, although not statistically significant.

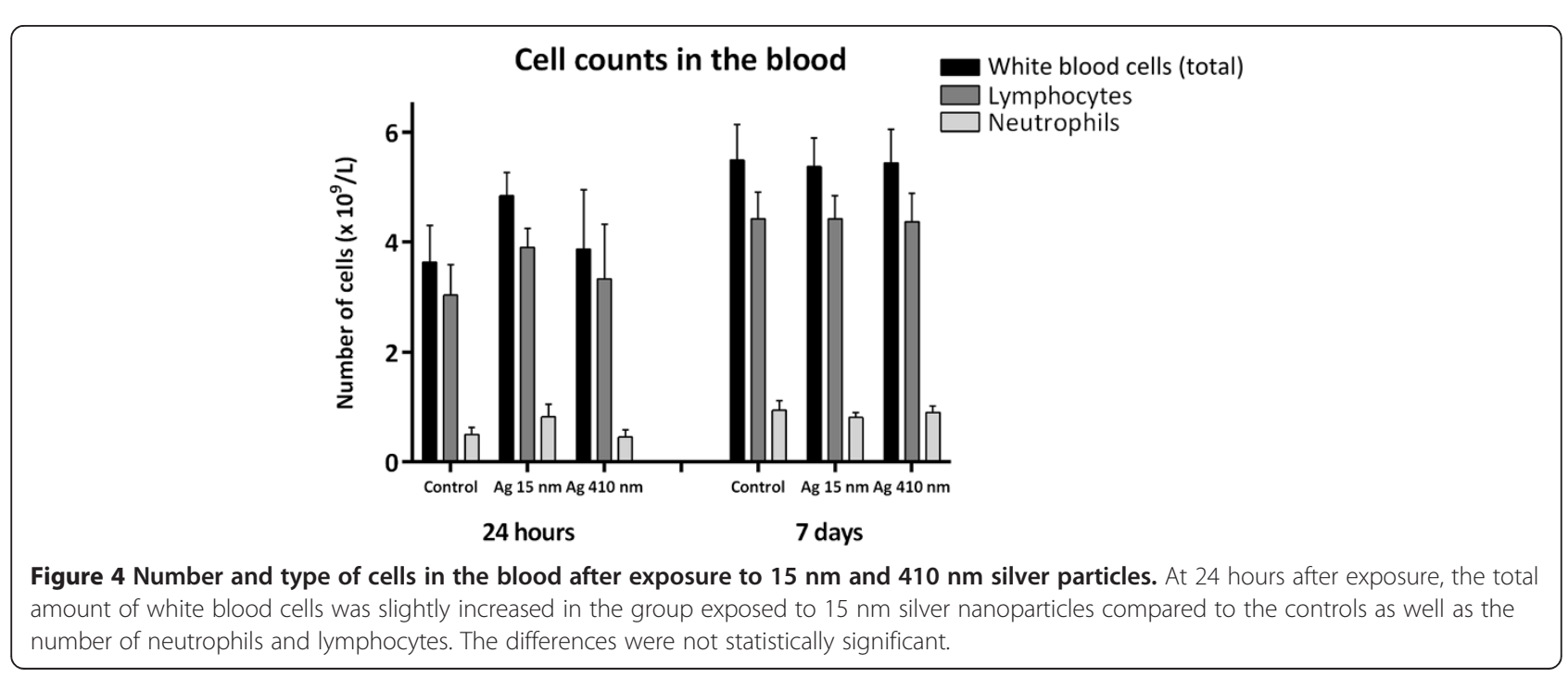




\section{Cell counts in the BALF}

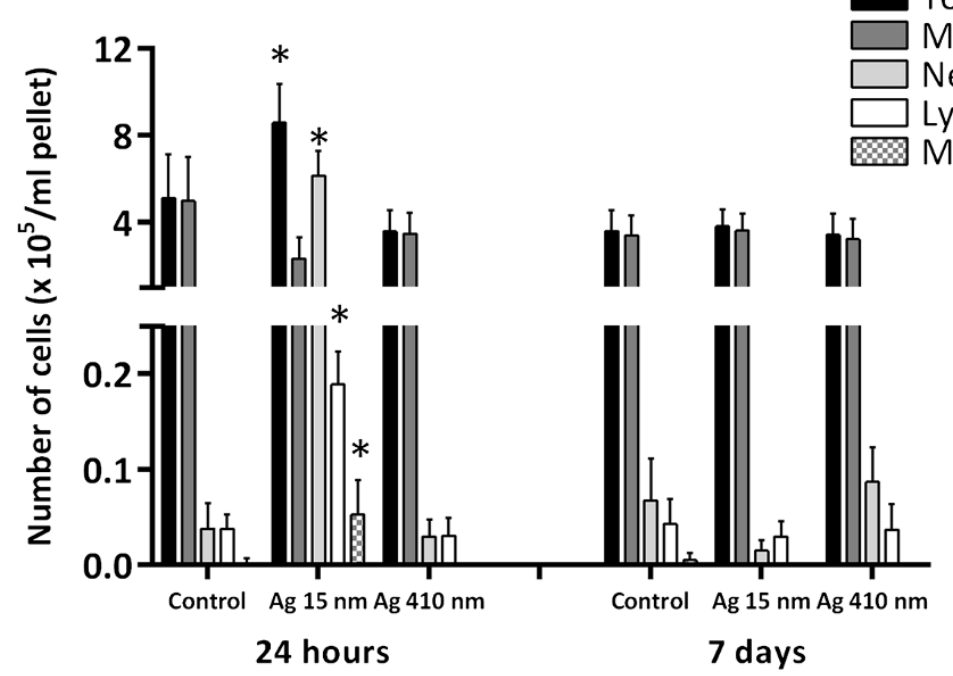

Figure $\mathbf{5}$ Cell counts in the BALF of rats. The group exposed to $15 \mathrm{~nm}$ silver particles had an increased number of total cells $(p=0.06)$, neutrophils $(p<0.01)$, lymphocytes $(p<0.05)$ and monocytes $(p<0.01)$ compared to the control group at 24 hours after exposure. Compared to the group exposed to $410 \mathrm{~nm}$ silver particles, the increased numbers of total cells $(p<0.05)$, neutrophils $(p<0.01)$, lymphocytes $(p<0.05)$ and monocytes $(p<0.001)$ were also significant. The increased cell numbers returned to normal at 7 days after exposure.

For the groups exposed to $15 \mathrm{~nm}$ silver nanoparticles, the cell counts were significantly different between 24 hours and 7 days after exposure, for all cell types. Compared to 24 hours after exposure, the total cell number, neutrophils, lymphocytes and monocytes all significantly decreased and the number of macrophages, multi-nuclei macrophages significantly increased at 7 days after exposure.

\section{LDH and total protein in the BALF}

The supernatant of the BALF was used to determine lactate dehydrogenase $(\mathrm{LDH})$ release and total protein as markers for cell damage (Figure 7). At 24 hours after exposure, the groups exposed to $15 \mathrm{~nm}$ silver nanoparticles and $410 \mathrm{~nm}$ silver particles both showed significantly increased levels of total protein in the BALF compared to the controls $(p<0.01$ and $\mathrm{p}<0.05$ respectively). The level of LDH was doubled at 24 hours after exposure to $15 \mathrm{~nm}$ silver nanoparticles compared to both control $(p=0.05)$ and compared to $410 \mathrm{~nm}$ silver particles exposed animals $(p<0.05)$. At 7 days after exposure, the levels of both total protein and LDH in the BALF of the exposed animals decreased to control levels.

\section{Pro-inflammatory cytokines in the BALF}

The supernatant of the BALF was used to determine the level of pro-inflammatory cytokines. 12 different proinflammatory cytokines were selected: IL-1 $\beta$, IL-6, TNF- $\alpha$, IFN- $\gamma$, IL-13, GM-CSF, MCP-1, IL-12p70, IL-18, MIP-1a, MIP-2 and RANTES. Of these cytokines, only IL- $1 \beta$, MCP-1 and MIP-2 could be measured; all the other cytokines were and stayed below or around the detection level (Figure 8). Both IL-1 $\beta$ and MCP-1 were significantly increased 24 hours after exposure to $15 \mathrm{~nm}$ silver

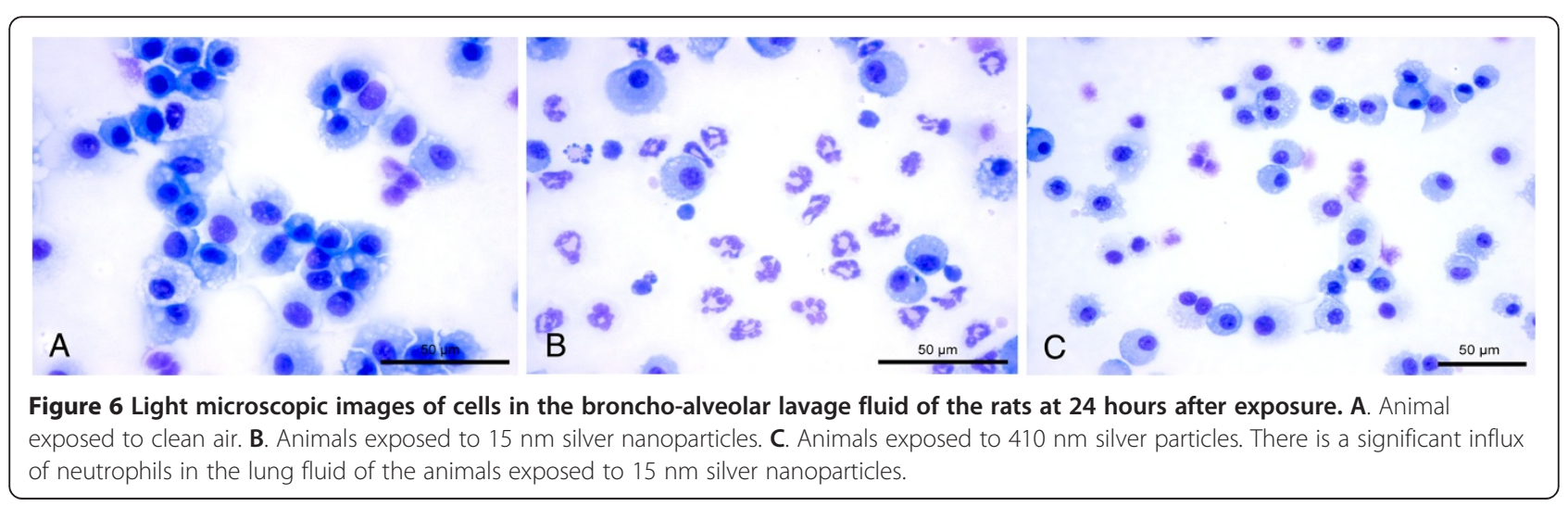




\section{LDH and protein in the BALF}

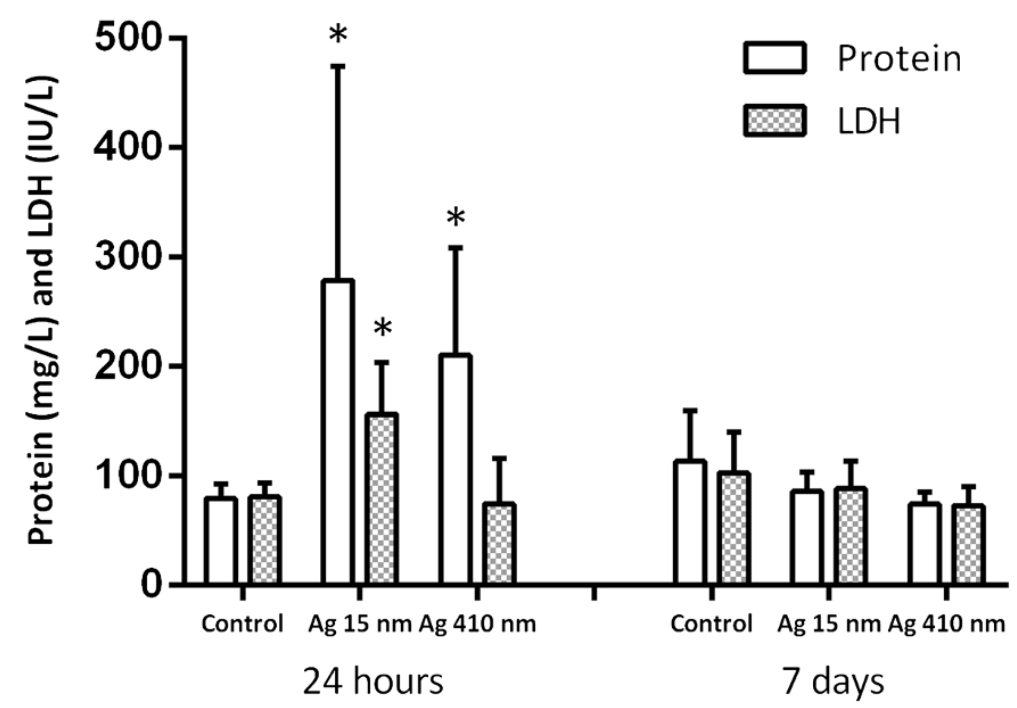

Figure 7 The level of total protein and LDH in the supernatant of the broncho-alveolar lavage fluid. At 24 hours after exposure, both the animals exposed to $15 \mathrm{~nm}$ silver particles and $410 \mathrm{~nm}$ silver particles showed a significant increase in the level of total protein compared to control ( $p<0.01$ and $p<0.05$, respectively). The total protein levels returned to normal at 7 days after exposure. The level of LDH was also significantly increased in the animals exposed to $15 \mathrm{~nm}$ silver nanoparticles at 24 hours after exposure compared to the control $(p<0.05)$ and to the animals exposed to $410 \mathrm{~nm}$ silver particles $(p<0.05)$.

nanoparticles. IL-1 $\beta$ was detected at $30.2 \mathrm{pg} / \mathrm{ml}$ for the $15 \mathrm{~nm}$ nanoparticles exposed group compared to $5.5 \mathrm{pg} / \mathrm{ml}$ for the controls $(p<0.05)$ and $4.9 \mathrm{pg} / \mathrm{ml}$ for the $410 \mathrm{~nm}$ particles exposed group $(p<0.05)$. In addition, the level of MCP-1 was increased in the rats exposed to $15 \mathrm{~nm}$ nanoparticles at 24 hours after exposure: $382.7 \mathrm{pg} / \mathrm{ml}$ compared to $61.6 \mathrm{pg} / \mathrm{ml}$ of the controls $(p=0.063)$ and $42.8 \mathrm{in}$ rats exposed to $410 \mathrm{~nm}$ silver particles $(p<0.01)$. The level of MIP-2 was significantly decreased to $26.5 \mathrm{pg} / \mathrm{ml}$ after 24 hours after exposure to $15 \mathrm{~nm}$ silver nanoparticles

\section{Pro-inflammatory cytokines in the BALF}

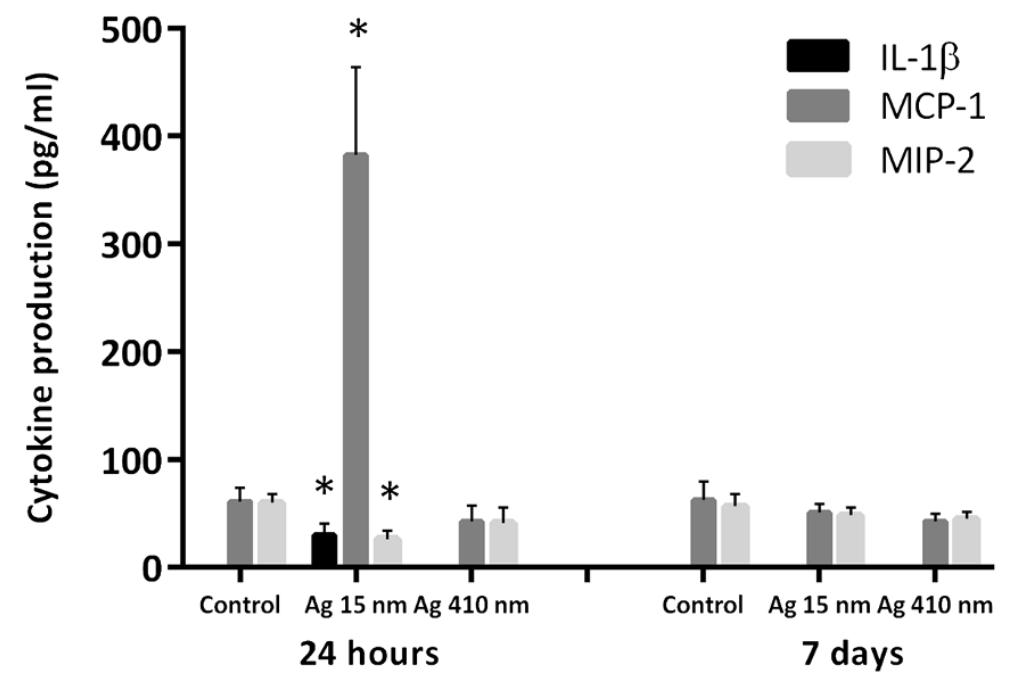

Figure 8 Cytokine level in the broncho-alveolar lavage fluid. The animals exposed to $15 \mathrm{~nm}$ silver nanoparticles had significantly increased levels of IL-1 $\beta(p<0.05)$, MCP-1 $(p=0.06)$ and MIP-2 $(p<0.01)$ in the BALF at 24 hours exposure compared to the controls. At 24 hours after exposure, the levels of IL-1 $\beta(p<0.05)$ and MCP-1 $(p<0.01)$ were also significantly increased compared to the animals exposed to $410 \mathrm{~nm}$ silver particles. At 7 days after exposure, the cytokine levels returned to normal. 
compared to the level of $60.2 \mathrm{pg} / \mathrm{ml}$ in the controls $(p<$ $0.01)$. The changes in IL-1 $\beta$, MCP-1 and MIP-2 levels at 24 hours after exposure to $15 \mathrm{~nm}$ silver nanoparticles recovered at 7 days after exposure, when no significant differences were observed in any of the cytokine levels measured between the different exposure groups. There were no significant differences between the group exposed to $410 \mathrm{~nm}$ silver particles and the controls at both 24 hours and 7 days after exposure.

\section{Oxidative stress in the lungs}

The levels of total glutathione, oxidized (GSSG) and reduced (GSH) glutathione were measured in the homogenate of the rinsed right lung of all the rats (Figure 9). The level of total glutathione was significantly increased at 24 hours after exposure to $15 \mathrm{~nm}$ silver nanoparticles compared to the controls $(p<0.01)$ and compared to the group exposed to $410 \mathrm{~nm}$ silver particles $(p<0.05)$. The level of reduced glutathione was also significantly increased at 24 hours after exposure to $15 \mathrm{~nm}$ silver nanoparticles compared to the controls $(p<0.01)$ and the $410 \mathrm{~nm}$ exposed group $(p<0.05)$, whereas the level of oxidized glutathione was not. The ratio of GSH/GSSG was not significantly different between any of the exposure groups. 7 days after exposure, the level of total glutathione and reduced glutathione in the group exposed to $15 \mathrm{~nm}$ silver nanoparticles returned to control levels.

\section{Discussion}

In this short-term inhalation study, silver nanoparticles of two different sizes were tested to determine the differences in the lung deposition, tissue distribution and adverse effects. Exposure to $15 \mathrm{~nm}$ silver nanoparticles induced a moderate inflammatory response at 24 hours after the end of the exposure period. All the observed effects disappeared at 7 days after exposure. The most pronounced observed effect was the influx of neutrophils at 24 hours after exposure to $15 \mathrm{~nm}$ silver nanoparticles, which was about 175 times larger compared to the controls. In addition, we found release of proinflammatory cytokines, an increase in total glutathione and the presence of silver nanoparticles inside lung cells. In contrast, the $410 \mathrm{~nm}$ particles induced none of these effects in the lung, clearly demonstrating a particle size dependent difference in the induction of pulmonary inflammation.

There are two main reasons to explain the noted differences in effects by the two silver particles. First, the differences in effects may be attributed to the differences in lung deposition of the smaller versus the larger silver particles. The total lung deposit as measured by HRICP-MS was $5.5 \mu \mathrm{g}$ for the $15 \mathrm{~nm}$ silver nanoparticles and $8.5 \mu \mathrm{g}$ for the $410 \mathrm{~nm}$ silver particles at 24 hours after the end of the exposure period. According to the MPPD model, the fraction that reaches the alveoli is about 5.5 times higher for the $15 \mathrm{~nm}$ nanoparticles compared to the $410 \mathrm{~nm}$ particles. Based on the HR-ICP-MS results we estimated the amount of $15 \mathrm{~nm}$ silver nanoparticles present in the alveoli was $7.9 \times 10^{6}$ particles per $\mathrm{mm}^{3}\left(2.1 \mu \mathrm{g}\right.$ mass or $5.8 \times 10^{12} \mathrm{~nm}^{2} / \mathrm{cm}^{3}$ surface area) and the number of $410 \mathrm{~nm}$ silver particles was 118 particles per $\mathrm{mm}^{3}\left(0.6 \mu \mathrm{g}\right.$ mass or $6.2 \times 10^{10} \mathrm{~nm}^{2} / \mathrm{cm}^{3}$ surface area). Therefore, the number of bioavailable $15 \mathrm{~nm}$ nanoparticles in the alveoli is about 66,000 times larger compared to the $410 \mathrm{~nm}$ particles, resulting in a higher interaction probability with cells.

Comparing same mass deposits of microparticles and nanoparticles, the latter contains a much higher number of particles that need to be cleared. In addition, the smaller silver nanoparticles deposit deeper in the lungs where they are less efficiently cleared compared to the larger particles that deposit more in the conducting airways

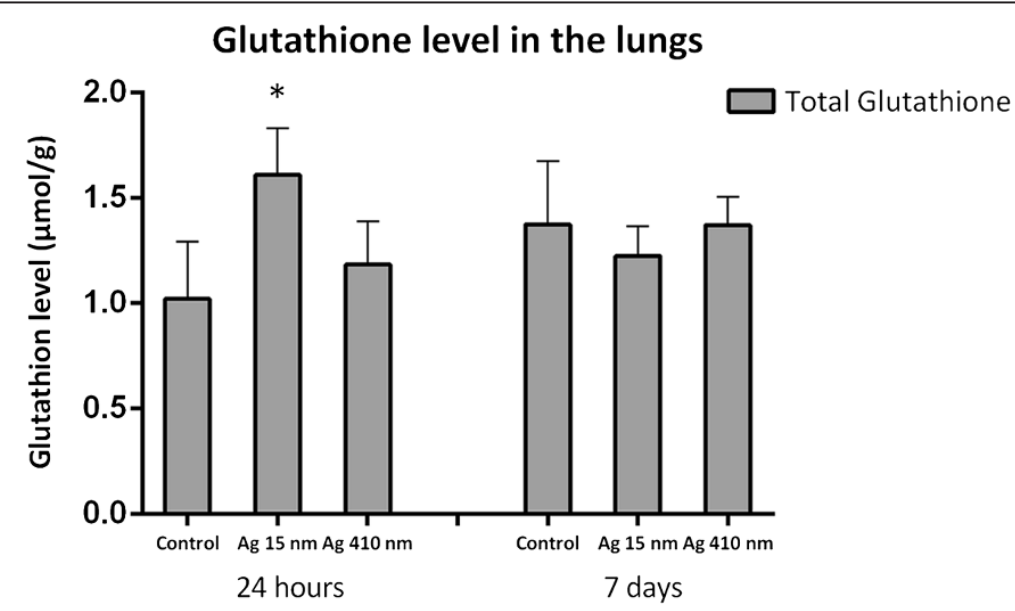

Figure 9 Glutathione production in the lungs of rats. At 24 hours after exposure, the total glutathione production in the $15 \mathrm{~nm}$ silver nanoparticles exposed group was significantly elevated compared to the controls $(p<0.01)$ and the $410 \mathrm{~nm}$ silver particles exposed group $(p<0.05)$. 
where they are more easily cleared [16-18,21-24]. Moreover, the phagocytosis of nanoparticles by macrophages is less efficient [25-27] and slower compared to microparticles [28-30]. Our results, however, show a clearance from the lungs of $62 \%$ of the $15 \mathrm{~nm}$ nanoparticles compared to $31 \%$ of the $410 \mathrm{~nm}$ particles at 7 days after exposure. The higher clearance rate of the smaller particles might be explained by translocation from the lungs of the smaller silver nanoparticles or the released ions to the blood or interstitium. This is further supported by the detection of silver in the liver of animals at 24 hours after exposure to $15 \mathrm{~nm}$ silver nanoparticles, indicating systemic availability of silver particles or ions. This was not detected after exposure to the $410 \mathrm{~nm}$ silver particles.

Previous inhalation studies with nanosilver showed a dose-dependent increase in silver concentration in the liver $[11,13,15]$ and even a low translocation to the brain and olfactory bulb $[11,15]$. In one study, the amount of silver in the brain and olfactory bulb was $2.2 \mathrm{ng} / \mathrm{g}$ and $6.97 \mathrm{ng} / \mathrm{g}$, respectively, after exposure to the highest dose tested of $61 \mu \mathrm{g} / \mathrm{m}^{3}$ [11]. In the other study, the amount of silver in the brain and olfactory bulb was $18.63 \mathrm{ng} / \mathrm{g}$ and $30.48 \mathrm{ng} / \mathrm{g}$ at the highest dose tested of $515 \mu \mathrm{g} / \mathrm{m}^{3}$ [15]. In both studies, the tissue distribution of silver was detected by atomic absorption spectrophotometer. The reported level of silver is too low to detect with the HR-ICP-MS, which has a detection limit of $0.01 \mu \mathrm{g} / \mathrm{g}$, possibly explaining why we did not detect any silver in the brain or olfactory bulb. It should be noted that both detection methods do not distinguish between silver particles and silver ions.

The second reason for the observed differences in effects between the $15 \mathrm{~nm}$ and $410 \mathrm{~nm}$ silver particles is the difference in particle dissolution. It is known that smaller particles dissolve faster compared to larger particles because of the high surface to volume ratio [31]. Several in vitro studies determined the dissolution rate of silver nanoparticles. In the study of Ma et al. [31], the dissolution of silver nanoparticles ranged from $1 \%$ for the larger particles of $80 \mathrm{~nm}$ to $60 \%$ for the smallest particles of $5 \mathrm{~nm}$ at $\mathrm{pH} 8$ during three and two months incubation, respectively. However, there was no constant release of silver ions per unit of surface area, indicating that surface area alone did not explain the dissolution of silver nanoparticles [31]. According to this and other studies [31-35], the dissolution of silver nanoparticles depends on their particle size, the $\mathrm{pH}$ of the solution, the ions present in the solution (e.g. sulphate, chloride and phosphate causing precipitations with silver ions or catalysing dissolution), aggregation state and the incubation time. Giving these in vitro results, the dissolution rate of the $15 \mathrm{~nm}$ silver nanoparticles will probably be higher compared to the $410 \mathrm{~nm}$ silver particles resulting in an increased ion release. None of these studies report complete dissolution of silver nanoparticles, the effects observed after exposure to silver nanoparticles can be induced by the released ions, the silver nanoparticles itself or a combination of both.

In a study of Pratsinis et al. [36], the toxicity of silver nanoparticles in the presence of their released ions, and the released ions alone was tested in vitro. For small silver nanoparticles with a size below $10 \mathrm{~nm}$, the released silver ions from the surface dominated the cytotoxicity whereas for larger silver nanoparticles the interactions with silver particles dominated the toxicity [36]. According to Beer et al. [37], at silver ion fractions $\leq 2.6 \%$ the silver nanoparticles contribute to the observed toxicity while at silver ion fractions $\geq 5.5 \%$ the silver nanoparticles do not add additional toxicity in vitro [37]. In a recent published study [38], oropharyngeal aspiration in mice of $20 \mathrm{~nm}$ citrate-coated silver nanoparticles caused pulmonary inflammation indicated by neutrophil influx and the release of pro-inflammatory cytokines, whereas $110 \mathrm{~nm}$ citrate-coated silver particles caused a smaller neutrophil influx, only at the highest dose tested, and no release of pro-inflammatory cytokines. At 21 days after exposure, the silver content in the lungs did not differ between $20 \mathrm{~nm}$ and $110 \mathrm{~nm}$ silver particles. In addition, for both particle sizes, there was no silver detected in any of the other selected organs and tissues. Solubility test showed that about $4 \%$ of the $20 \mathrm{~nm}$ nanoparticles and $2 \%$ of the $110 \mathrm{~nm}$ particles dissolved in 24 hours. Therefore, the authors concluded the larger pulmonary inflammation caused by the $20 \mathrm{~nm}$ silver nanoparticles is due to the higher bioavailability of silver ions. However, the effects of $20 \mathrm{~nm}$ silver nanoparticles were stronger compared to the effects of silver nitrate indicating the particles itself contributed to the observed effects. In contrast to these results, the $110 \mathrm{~nm}$ silver particles caused mild sub-chronic effects in the lungs at 21 days after exposure, which might be caused by a slower and more persistent silver ions release [38]. Similar to these studies, it is likely that the release of silver ions contributed to the observed effects after exposure to $15 \mathrm{~nm}$ silver nanoparticles in the present study. To further elucidate the mechanism of the silver nanoparticle toxicity, the dissolution behaviour of silver nanoparticles inside cells should be investigated in detail.

In our study, we could detect by TEM silver nanoparticles in the lung tissue of rats at 24 hours after exposure to $15 \mathrm{~nm}$ silver nanoparticles. At 24 hours after exposure to $410 \mathrm{~nm}$ silver particles, we could not detect silver particles in the lungs because the number of particles was too low. The detected silver nanoparticles had a particle size of $15-20 \mathrm{~nm}$ after silver enhancement, indicating their size in the lung tissue was smaller than $5 \mathrm{~nm}$ before enhancement. In combination with the literature on the dissolution of silver nanoparticles, these EM results 
are an indication that the silver nanoparticles probably partially dissolved after deposition resulting in a decrease in particle size and the release of silver ions. The dissolution might occur extra-cellular in the lung lining fluid and intra-cellular in vesicles in epithelial cells or macrophages. Besides the release of silver ions, we believe the silver nanoparticles itself may also have contributed to the observed effects because the TEM images show the presence of silver nanoparticles inside lung cells. The $15 \mathrm{~nm}$ silver nanoparticles in our study dissolved over time resulting on the one hand in the release of toxic silver ions and on the other hand in a decrease in particle size to $<5 \mathrm{~nm}$ which gives the particles the opportunity to pass the cellular membranes and the nuclear pores. Previous studies report that particles smaller than $5 \mathrm{~nm}$ possibly can pass the nuclear pores [39], while particles of $20 \mathrm{~nm}$ do not reach the nucleus and could be detected in vesicles and lamellar bodies in vitro [40]. Once inside the cells and eventually inside the nucleus, silver nanoparticles are a continued source of ion release, leading to more damage compared to silver ions released from silver nitrate [41]. The intracellular ion release has been reported previously as the Trojan-horse type mechanism [42,43]; nanoparticles can more easily enter the cells compared to the ions itself. The higher dissolution rate, in combination with the higher alveolar deposition of the $15 \mathrm{~nm}$ nanoparticles, might explain why the $15 \mathrm{~nm}$ nanoparticles caused toxicity and the $410 \mathrm{~nm}$ particles did not. Based on the results of the present study, it is not possible to quantify how much of the observed effects can be attributed to the difference in alveolar deposition and how much of the effects can be attributed to cellular uptake and ion release.

Findings of particle size related pulmonary inflammation are not limited to silver nanoparticles. Other inhalation studies with titanium dioxide, carbonaceous, nickel oxide, zinc oxide, ferric oxide, aluminium oxyhydroxide, quartz and cerium oxide particles also focused on the influence of particle size on the induction of pulmonary inflammation [27,44-52]. Indeed, several studies report that smaller nanoparticles caused a greater inflammatory response compared to larger particles when the same mass dosage was administered [27,44-48]. However, although particle size will affect the site and amount of deposited material, it seems that the local dose alone cannot explain the differences in toxicity. Solubility will at least be one of the other variables in an equation that would allow predicting adverse effects of nanoparticles after inhalation.

\section{Conclusion}

The results of the present short-term inhalation study of uncoated silver particles indicate that particle size is an important characteristic that determines the induction of pulmonary inflammation. Exposure to $15 \mathrm{~nm}$ silver nanoparticles induced moderate pulmonary inflammation at 24 hours after exposure, whereas $410 \mathrm{~nm}$ silver particles did not. The lung deposition of the $410 \mathrm{~nm}$ silver particles was mainly in the upper airways; the number of particles deposited in the alveoli was calculated to be 66,000 times higher for the $15 \mathrm{~nm}$ silver nanoparticles. TEM analysis showed the presence of silver nanoparticles in lung cells that were decreased in particle size, demonstrating the in vivo dissolution of silver nanoparticles. Altogether, these findings strongly suggest that size-related silver nanoparticle induced pulmonary inflammation is a consequence of both size related lung deposition and dissolution rate.

\section{Methods}

\section{Test material and characterization}

The test atmosphere was produced by mixing silver nanoparticles with HEPA filtered and conditioned (50\% $\mathrm{RH}, 21^{\circ} \mathrm{C}$ ) compressed air. Depending on the target particle size, one of two types of particle generators was used. The silver nanoparticles were produced by a Palas GFG 1000 (Palas GmbH, Karlsruhe, Germany) spark generator fitted with silver tipped copper electrodes. To generate the $15 \mathrm{~nm}$ nanoparticles the output of the generator was immediately diluted in conditioned air. Oxygen was added to the dilution air to compensate for the argon flow from the Palas, a final concentration of $20 \%$ oxygen in the airflow was maintained. The particle number concentration was controlled by setting the Palas spark frequency. The final condition of the aerosol (55\% $\mathrm{RH}, 21^{\circ} \mathrm{C}$ ) was set by adjusting the relative humidity of the mixing air (Figure 10). $200 \mathrm{~nm}$ silver particles were purchased by NanoComposix, inc. San Diego, USA. The $200 \mathrm{~nm}$ silver particles were polyvinylpyrrolidone (PVP)coated and supplied in solution of $1 \mathrm{mg} / \mathrm{ml}$ in MilliQ water. The silver particle solution was forced through a small nozzle of a Schlick spray nozzle where it was broken up in small droplets (nebulized) by compressed air. The flow of the solution was controlled using a $20 \mathrm{ml}$ Terumo syringe and a syringe pump (TSE model 540200, Bad homburg, Germany). The nebulized flow was mixed with compressed air in a heated mixing tube. After mixing and drying, the aerosol passed through a tube oven $\left(700^{\circ} \mathrm{C}\right)$ to fuse the aggregates into a single particle. The heat of the oven removed the PVP-coating of the silver particles. After the oven, the aerosol diluted further with conditioned air and was allowed to cool. The mass concentration was controlled by adjusting the syringe pump motor speed and thus the flow of the solution. The final condition of the aerosol $\left(55 \% \mathrm{RH}, 21^{\circ} \mathrm{C}\right)$ was set by adjusting the relative humidity of the final mixing air (Figure 11). 


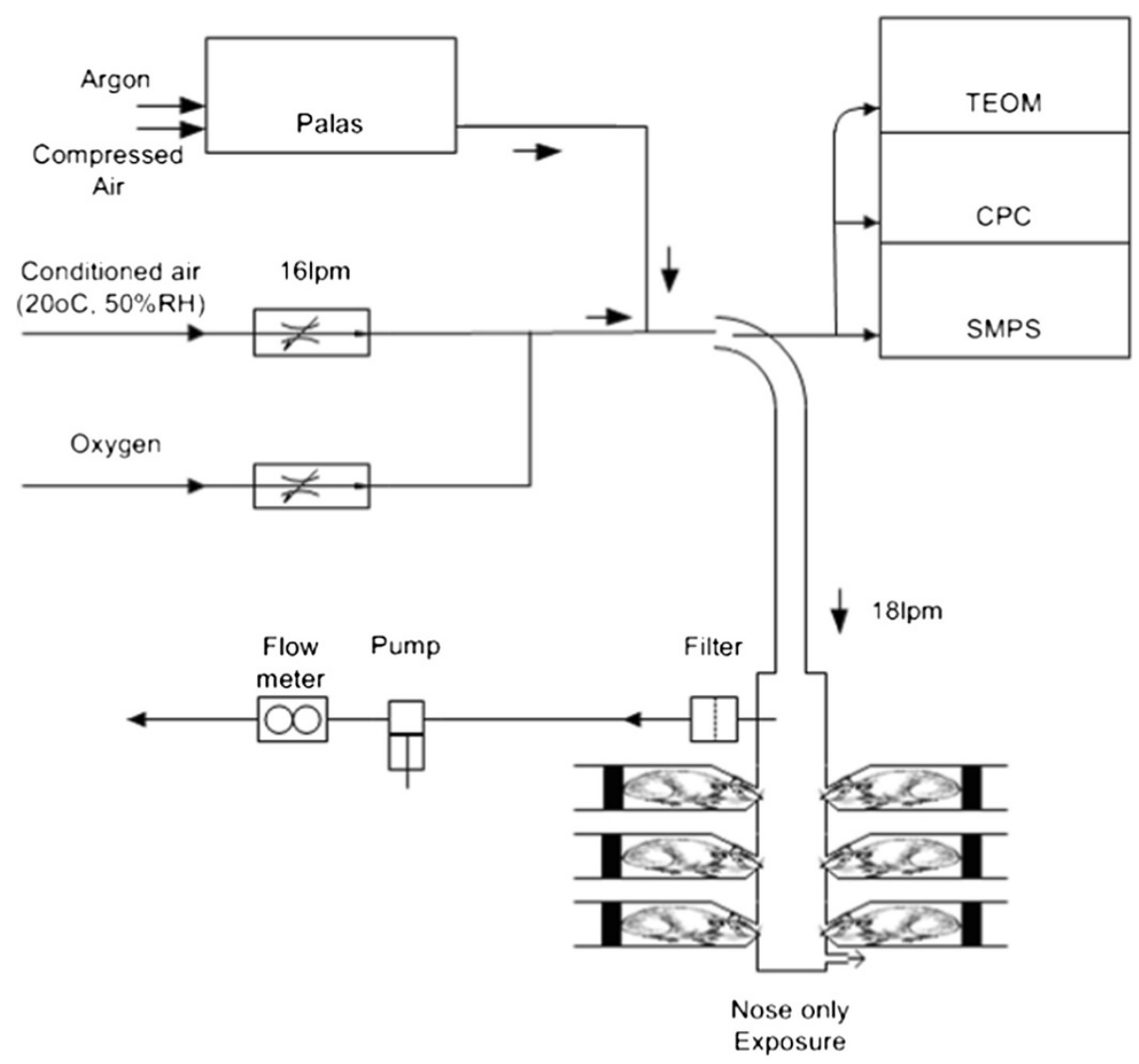

Figure 10 Palas spark generator setup for the nose-only exposure to $15 \mathrm{~nm}$ silver nanoparticles. The silver nanoparticles are generated by the Palas spark generator and subsequently mixed with conditioned air and oxygen. Particle size, number and mass are continuously monitored.

Several measurements of the test atmosphere were performed during the exposure. In the main flow upstream of the nose only unit particle mass concentration, number concentration, and particle size distribution were measured. The particle mass concentration was determined by time aggregated gravimetric with Teflon R2PJ047 filter (Pall corp., Ann Arbor MI, USA) and by tapered element oscillating microbalance (TEOM) series1400 (Rupprecht \& Patashnick, New York, USA). The particle number concentration was measured over time by a condensation particle counter (CPC) 3022 (TSI inc., St Paul MN, USA). Particle size distribution was monitored over time by an OPS 3330 (TSI inc., St Paul MN, USA), a scanning mobility particle sizer (SMPS) 3080 with 3085 Nano DMA (TSI inc., St Paul MN, USA) and a MOI Model No. 110 (MSP corp, Minneapolis MN, USA). Temperature and relative humidity were determined by a Vaisala M170 (Vaisala Oyj, Helsinki, Finland). The particle size was confirmed by scanning electron microscopy (SEM) using a Nova Nanolab 600 Dualbeam (FEI, Eindhoven, the Netherlands) (Figure 1). In addition, the gravimetric mass concentration was determined. A
Sartorius MC-5 microbalance (Sartorius, Goettingen, Germany) was used in controlled relative humidity (40 $45 \%)$ and temperature $\left(21-23^{\circ} \mathrm{C}\right)$ conditions to do the mass measurements, the filters were weighed before and after each exposure. Laboratory and field blanks were used for quality assurance. The filter volume flow was measured with dry gas meters (Gallus 2000 G1.6, Actaris Meterfabriek B.V., Dordrecht, the Netherlands).

\section{Animals}

The Animal Ethical Committee of the National Institute for Public Health and the Environment (Bilthoven, the Netherlands) approved the experimental design of the animal study at the 6th of July 2012. Healthy male Fischer rats (F344/DuCrl) were supplied by Charles River (Sulzfeld, Germany). The animals were kept under specific pathogen free (SPF) conditions. After an acclimatization period of two weeks, the animals were 10 weeks old at the start of the experiment. The rats were randomly allocated to the control and the test groups. During exposure, the animals were restrained in nose-only tubes $(\mathrm{CH}$ technologies, Westwood NJ, USA) fixed to the inhalation system. 


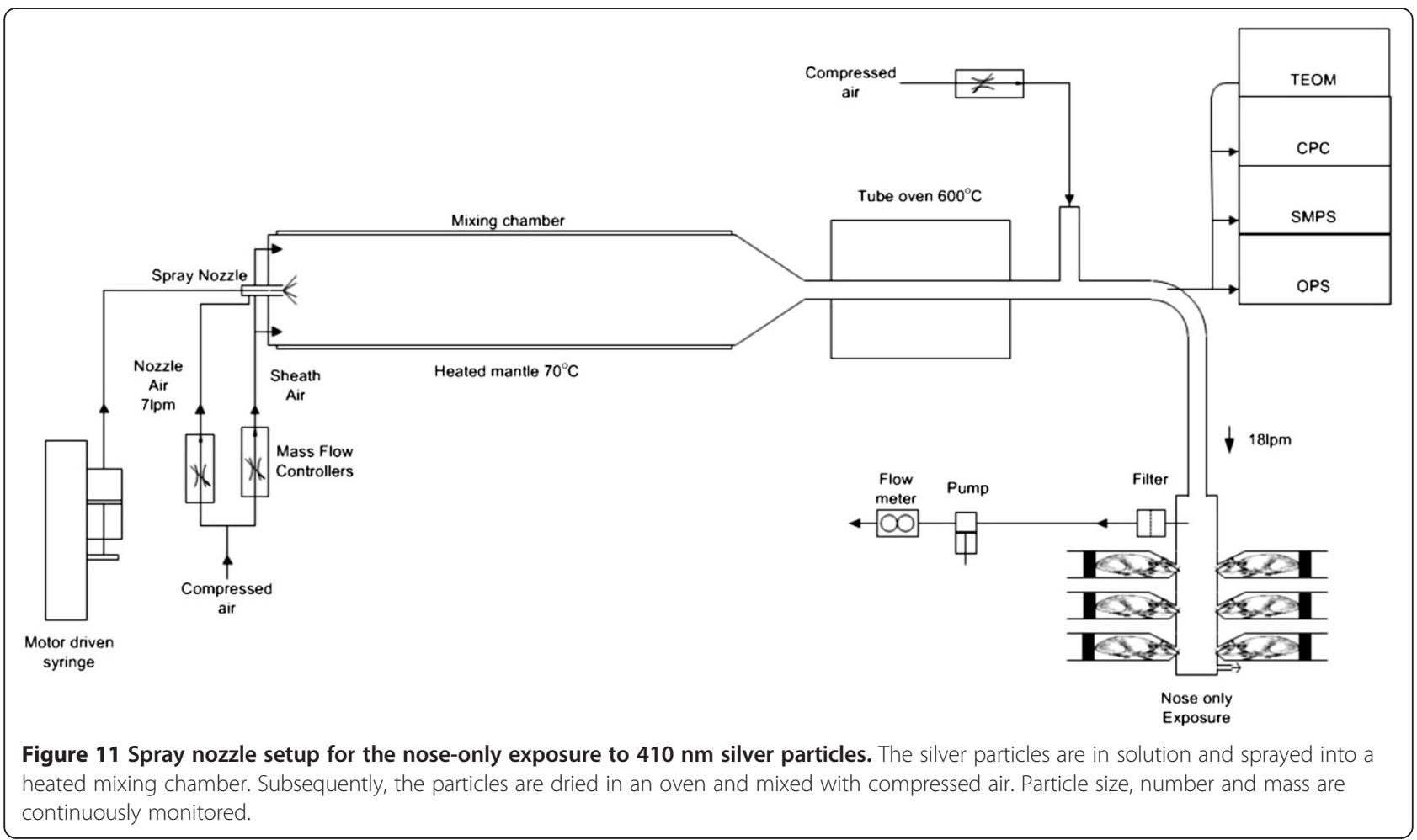

When not exposed, animals were housed up to 3 animals in macrolon III cages with filtertops to prevent dust entering the cages (bedding material: Lignocel S8-15, Altromin Spezialfutter $\mathrm{GmbH} \& \mathrm{Co}$. KG). The animal room was air-conditioned with a 12 hours light- 12 hours dark cycle, the temperature ranging from 20 to $24^{\circ} \mathrm{C}$ with relative humidity ranging from $30-70 \%$. Except during exposure, certified feed CRM (SDS Diets, UK) and water were available ad libitum. Before start of the exposure period, all animals were acclimatized to the nose only tubes on 3 consecutive days for 1 hour per day. At 24 hours and 7 days after the last exposure, rats were weighed, anesthetized by a single intraperitoneal injection of ketamine $(75 \mathrm{mg} / \mathrm{kg}$ ) and xylazine $(10 \mathrm{mg} / \mathrm{kg})$ and subsequently exsanguinated via the abdominal aorta.

\section{Experimental design}

The rats were nose-only exposed for 6 hours per day, 4 consecutive days to fresh air, $15 \mathrm{~nm}$ silver nanoparticles or $410 \mathrm{~nm}$ silver nanoparticles, 12 rats per exposure group. Of each exposure group, 6 rats were sacrificed 24 hours after exposure and the other 6 rats were sacrificed 7 days after exposure. During nose-only inhalation, rats have a breathing pattern that results in a more realistic internal exposure than a single high dose in intratracheal instillation and oropharyngeal aspiration or possible additional oral exposure in whole-body exposure chambers.
Quantification of silver in tissues by high resolution inductively coupled plasma mass spectrometry (HR-ICP-MS) The presence of silver in the lungs, liver, spleen, kidneys, brain, testis and lung associated lymph nodes was determined by high resolution inductively coupled plasma mass spectrometer (HR-ICP-MS) [53,54]. Samples of homogenized tissue (max. $0.5 \mathrm{~g}$ ) were completely dissolved on a block heater (Stuart SBH200D, supplied by Omnilabo, Breda, The Netherlands) for 24 hours at $120^{\circ} \mathrm{C}$ after the direct addition of aqua regia $(0.5 \mathrm{~mL} 60 \%$ nitric acid, ultrapure, and $1.5 \mathrm{~mL} \mathrm{30 \%} \mathrm{hydrochloric} \mathrm{acid,} \mathrm{ultra-}$ pure) and afterwards diluted. The silver concentration in the digests was determined using high resolution inductively coupled plasma mass spectroscopy (HR-ICPMS; Element XR, Thermo Fisher Scientific, Bremen, Germany). Both silver isotopes $\left({ }^{107} \mathrm{Ag}\right.$ and $\left.{ }^{109} \mathrm{Ag}\right)$ were measured in the low-resolution mode. External calibration curves of the interference-free silver isotopes were used for quantification. On-line addition and correction with an internal standard (rhodium with the measured isotope ${ }^{103} \mathrm{Rh}$ in the low-resolution mode) was applied too. The results of ${ }^{107} \mathrm{Ag}$ were reported and the results of ${ }^{109} \mathrm{Ag}$ were used for control. Sample pre-treatment and analysis were carried out in a cleanroom facility class 100000 .

\section{Estimated deposited dose in lungs using Multi Path Particle Dosimetry model (MPPD model)}

To estimate the fractions of deposited dose in the head, tracheobronchial, and alveolar region of the rats, the 
multiple path particle dosimetry model (MPPD model) was used [16]. We used the default parameters of the model for rats, i.e., a forced respiratory capacity of $4 \mathrm{ml}$, head volume of $0.42 \mathrm{ml}$, nasal breathing, tidal volume of $2.1 \mathrm{ml}$, and a breathing frequency of $102 / \mathrm{min}$. The inspiratory fraction was 0.5 , and no pause was entered. Calculations were done using the count median diameter (CMD), geometric SD, the mass concentration, and a density of $10.49 \mathrm{~g} / \mathrm{cm}^{3}$.

\section{Electron microscopy of the lung}

Of two animals of each group, the left lung was cut out with the bronchus attached and fixed by pressure $(2 \mathrm{kPa}$ for 1 hour) with half-strength Karnovsky fixative (0.08 M Sodium-cacodylate buffer, $2.5 \%$ glutaraldehyde, $0.025 \mathrm{mM}$ $\mathrm{CaCl}_{2}, 0.05 \mathrm{mM} \mathrm{MgCl}_{2}$ ) for electron microscopy. After two days, the fixative was replaced with $2 \%$ paraformaldehyde in sodium-cacodylate buffer for storage. Of each lung, three slices of about $1-1.5 \mathrm{~mm}$ were cut out at the top, middle and bottom of the lung for further analysis. The tissue slices were post-fixed by osmium potassium ferro-cyanide solution $(0.1 \mathrm{M}$ sodium-cacodylate buffer, $1 \%$ osmium tetra-oxide, $1.5 \%$ potassium ferrocyanide). Next, the tissue slices were dehydrated in aceton series, cut in smaller pieces and subsequently embedded in epon. The epon was polymerized at $60^{\circ} \mathrm{C}$. The epon blocks were trimmed prior to sectioning. During sectioning, ultrathin sections of $70 \mathrm{~nm}$ were sectioned and put on $3 \mathrm{~mm}$ hexagonal copper grids coated with a formvarfilm. The sections were analysed by transmission electron microscopy (TEM) (Tecnai 10, 100 kV, FEI, Eindhoven, the Netherlands).

\section{Silver enhancement}

A silver enhancement procedure was used to increase the particle size of the silver nanoparticles in the lung tissue to make it possible to detect the silver nanoparticles with electron microscopy. The silver enhancement reagents were purchased at Aurion and performed on grid according to manufacturer's instructions (Wageningen, the Netherlands).

\section{Clinical examinations}

The animals were examined three times on exposure days (before, during and after exposure) and once daily during the periods before and after exposure. The clinical examination included examination of attitude, animal fur, activity level, food and water intake, and faeces and urine production. The body weight of the animals was determined upon arrival, at the start of the exposure period and at the day of sacrifice.

\section{Hematology analysis}

Blood samples were collected in EDTA-containing tubes and in citrate vials for analysis of cell types and inflammatory markers in the blood. The level of Fibrinogen in the citrate plasma was measured using a rat Fribrinogen ELISA kit (GenWay Biotech, Inc., San Diego, USA) according to manufacturer's instructions.

\section{Histopathology}

The lungs fixed with half-strength Karnovsky fixative were also used for histopathology. Of these lungs a thin slice was made over the length of the tissue, embedded in paraffin and stained by haematoxylin-eosin for histopathology analysis.

\section{Bronchoalveolar lavage fluid (BALF) analysis}

The left lung of the rats was bound just below the bifurcation of the trachea and the right lung was cannulated via the trachea. Bronchoalvelar lavage was performed in situ by infusing the right lung three times with $27 \mathrm{ml} / \mathrm{kg}$ physiological saline. The retrieved bronchoalveolar lavage fluid (BALF) was kept on ice and centrifuged for 10 minutes at $400 \mathrm{~g}$. The pellet was resuspended in physiological salt for analysis of the total cell number and cell differentials. Cytospin preparations were stained and evaluated microscopically for macrophages, polynuclear macrophages, polymorph nuclear neutrophils, lymphocytes, monocytes, eosinophils, and atypical cells. At least 400 cells were counted on each slide. The cellfree supernatant was collected to assess cell damage by measurement of total protein content and the release of lactate dehydrogenase (LDH) by Beckman Coulter autoanalyser Synchron LX20 (Beckman Coulter, Inc.) and to assess the induction of pro-inflammatory cytokines. The remainder of the supernatant was stored at $-80^{\circ} \mathrm{C}$.

\section{Measurement of pro-inflammatory cytokines}

The presence of pro-inflammatory cytokines IL-1beta, IL-6, TNF-alfa, IFN-gamma, IL-13, GM-CSF, MCP-1, IL12p70, IL-18, MIP-1a, MIP-2 and RANTES in the supernatant of the BALF was measured by a Bio-Plex Pro assay for rat cytokines according to manufacturer's instructions (Bio-Rad Laboratories, Inc.).

\section{Measurement of oxidative stress}

The induction of oxidative stress was determined by measuring the amount of reduced, oxidized and total glutathione in the lungs. The rinsed right lung was homogenized on ice in $4 \mathrm{ml}$ of Phosphate/EDTA buffer ( $\mathrm{pH}$ 7.5). Subsequently, the homogenate was centrifuged at $600 \mathrm{~g}$ for 10 minutes. To remove the proteins from the samples, the supernatant was mixed 1:1 with metaphosphorid acid, incubated for 15 minutes on ice, and centrifuged at $4000 \mathrm{rpm}$ for 10 minutes. The amount of reduced, oxidized and total glutathione was measured by Beckmann Coulter Autoanalyser in the supernatant. 


\section{Statistical analysis}

The raw data of the BALF was corrected for retrieved fluid. To compare the different exposure groups, the data was analysed by the Kruskal Wallis nonparametric test (Graphpad Prism). Statistical significance is indicated with $\mathrm{a} *(p=<0.05)$. In all graphs, error bars represent the standard deviation of the mean.

\section{Additional file}

Additional file 1: Figure S1. SMPS and OPS particle size distribution (left) and CPC particle number concentration (right) of $15 \mathrm{~nm}$ and 410 $\mathrm{nm}$ silver particles.

\section{Competing interests}

The authors declare that they have no competing interests.

\section{Authors' contributions}

$\mathrm{HB}$ designed the study. $\mathrm{HB}, \mathrm{MP}, \mathrm{AJFB}, \mathrm{PHBF}$ carried out the study. $\mathrm{HB}$ collected, analysed, interpreted data and drafted the manuscript. PK performed HR-ICPMS analysis and PHBF performed particle generation, both generated and interpreted data. AJFB, IG, MP and JAP contributed to the study design. JAP provided expert input on the electron microscopy data. MP, FRC, JAP and HVL have been involved in revising the manuscript critically for important intellectual content. All authors read and approved the final manuscript.

\section{Acknowledgements}

This work was supported by the project 'Integrated Risk Assessment of Nanomaterials' from the National Institute for Public Health and the Environment and by the NanoNextNL program 'Risk Analysis and Technology Assessment: Human Health Risks'. We would like to thank Liset J.J. de la Foneteyne for the BALF and haematology cells counts, Piet K. Beekhof for the analysis of the total protein, LDH and glutathione, and Henny W. Verharen, Hans J.C. Strootman, Ron F. Vlug, Christine M.R. Soputan, Jan Bos, Jolanda Rigters for their excellent technical assistance. In addition, we thank Karin E. M. Vocking, Elly G. van Donselaar for their assistance with the TEM imaging, Jose van den Dungen for assistance with sample pretreatments and D. A. Matthijs de Winter for the assistance with the SEM imaging

\section{Author details}

'Department of Toxicogenomics, Maastricht University, PO Box 616, Maastricht 6200, MD, the Netherlands. ${ }^{2}$ National Institute for Public Health and the Environment (RIVM), PO Box 1, Bilthoven 3720, BA, the Netherlands. ${ }^{3}$ Philips Innovation Services, High Tech Campus 11, Eindhoven 5656, AE, the Netherlands. ${ }^{4}$ Institute of Risk Assessment Sciences, Utrecht University, PO Box 80.163, Utrecht 3508, TD, the Netherlands. ${ }^{5}$ Cellbiology, Biology Department, Faculty of Science, University of Utrecht, PO box 80.056, Utrecht 3508, TB, the Netherlands.

Received: 4 March 2014 Accepted: 29 August 2014

Published online: 17 September 2014

\section{References}

1. Nanotechnologies PoE: Consumer Products Inventory. In Retrieved [June, 2014], from http://www.nanotechproject.org/cpi.

2. Maynard AD, Kuempel ED: Airborne nanostructured particles and occupational health. J Nanoparticle Res 2005, 7:587-614.

3. Christensen FM, Johnston HJ, Stone V, Aitken RJ, Hankin S, Peters S, Aschberger K: Nano-silver - feasibility and challenges for human health risk assessment based on open literature. Nanotoxicology 2010, 4:284-295.

4. Wijnhoven SWP, Peijnenburg WJGM, Herberts CA, Hagens WI, Oomen AG, Heugens EHW, Roszek B, Bisschops J, Gosens I, Meent D, Dekkers S, Jong WH, Zijverden M, Sips AJAM, Geertsma RE: Nano-silver - a review of available data and knowledge gaps in human and environmental risk assessment. Nanotoxicology 2009, 3:109-138.
5. Sotiriou GA, Pratsinis SE: Engineering nanosilver as an antibacterial, biosensor and bioimaging material. Curr Opin Chem Eng 2011, 1:3-10.

6. Sotiriou GA, Pratsinis SE: Antibacterial activity of nanosilver ions and particles. Environ Sci Technol 2010, 44:5649-5654.

7. Lok CN, Ho CM, Chen R, He QY, Yu WY, Sun H, Tam PK, Chiu JF, Che CM: Silver nanoparticles: partial oxidation and antibacterial activities. $J$ Biol Inorg Chem 2007, 12:527-534.

8. Morones JR, Elechiguerra JL, Camacho A, Holt K, Kouri JB, Ramirez JT, Yacaman MJ: The bactericidal effect of silver nanoparticles. Nanotechnology 2005, 16:2346-2353.

9. Xiu ZM, Zhang QB, Puppala HL, Colvin VL, Alvarez PJ: Negligible particlespecific antibacterial activity of silver nanoparticles. Nano Lett 2012, 12:4271-4275.

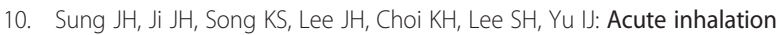
toxicity of silver nanoparticles. Toxicol Ind Health 2011, 27:149-154.

11. Ji JH, Jung JH, Kim SS, Yoon JU, Park JD, Choi BS, Chung YH, Kwon IH, Jeong J, Han BS, Shin JH, Sung JH, Song KS, YU IJ: Twenty-eight-day inhalation toxicity study of silver nanoparticles in Sprague-Dawley rats. Inhal Toxicol 2007, 19:857-871.

12. Stebounova LV, Adamcakova-Dodd A, Kim JS, Park H, O'Shaughnessy PT, Grassian VH, Thorne PS: Nanosilver induces minimal lung toxicity or inflammation in a subacute murine inhalation model. Part Fibre Toxicol 2011, 8:5.

13. Song KS, Sung JH, Ji JH, Lee JH, Lee JS, Ryu HR, Lee JK, Chung YH, Park HM, Shin BS, Chang HK, Kelman B, YU IJ: Recovery from silver-nanoparticleexposure-induced lung inflammation and lung function changes in Sprague Dawley rats. Nanotoxicology 2012, 7:169-180.

14. Sung JH, Ji JH, Yoon JU, Kim DS, Song MY, Jeong J, Han BS, Han JH, Chung YH, Kim J, Kim TS, Chang HK, Lee EJ, Lee JH, Yu IJ: Lung function changes in Sprague-Dawley rats after prolonged inhalation exposure to silver nanoparticles. Inhal Toxicol 2008, 20:567-574.

15. Sung JH, Ji JH, Park JD, Yoon JU, Kim DS, Jeon KS, Song MY, Jeong J, Han BS, Han JH, Chung YH, Chang HK, Lee JH, Cho MH, Kelman BJ, Yu IJ: Subchronic inhalation toxicity of silver nanoparticles. Toxicol Sci 2009, 108:452-461.

16. Asgharian B, Price $O$, Miller F, Subramaniam $R$, Cassee FR, Freijer J, van Bree L, Winter-Sorkina R: Multiple-Path Particle Dosimetry Model (MPPD v 2.11): A Model for Human and Rat Airway Particle Dosimetry. In Hamner Institutes for Health Sciences Applied Research Associates (ARA), National Institute for Public Health and the Environment (RIVM), and Ministry of Housing, Spatial Planning and the Environment, Editor. Raleigh, North Carolina, USA: Applied Research Associates (ARA); 2009.

17. ICRP: Human respiratory tract model for radiological protection. International Commission on Radiological Protection. ICRP Publication 66 1994, 24:1-3.

18. Carvalho TC, Peters Jl, Williams RO 3rd: Influence of particle size on regional lung deposition-what evidence is there? Int J Pharm 2011, 406:1-10.

19. Cassee FR, Muijser H, Duistermaat E, Freijer JJ, Geerse KB, Marijnissen JC, Arts $\mathrm{JH}$ : Particle size-dependent total mass deposition in lungs determines inhalation toxicity of cadmium chloride aerosols in rats. Application of a multiple path dosimetry model. Arch Toxicol 2002, 76:277-286.

20. Braakhuis HM, Park MV, Gosens I, De Jong WH, Cassee FR: Physicochemical characteristics of nanomaterials that affect pulmonary inflammation. Part Fibre Toxicol 2014, 11:18.

21. Geiser M, Kreyling WG: Deposition and biokinetics of inhaled nanoparticles. Part Fibre Toxicol 2010, 7:2

22. Oberdorster G: Dosimetric principles for extrapolating results of rat inhalation studies to humans, using an inhaled Ni compound as an example. Health Phys 1989, 57(Suppl 1):213-220.

23. Oberdorster G, Ferin J, Lehnert BE: Correlation between particle size, in vivo particle persistence, and lung injury. Environ Health Perspect 1994, 102(Suppl 5):173-179.

24. Geraets L, Oomen AG, Schroeter JD, Coleman VA, Cassee FR: Tissue distribution of inhaled micro- and nano-sized cerium oxide particles in rats: results from a 28-day exposure study. Toxicol Sci 2012, 127:463-473.

25. Phalen RF, Mendez LB, Oldham MJ: New developments in aerosol dosimetry. Inhal Toxicol 2010, 22(Suppl 2):6-14.

26. Oberdorster G, Pott F: Extrapolation from rat studies with environmental tobacco smoke (ETS) to humans: comparison of particle mass deposition and of clearance behavior of ETS compounds. Toxicol Lett 1987, 35:107-112 
27. Oberdorster G, Finkelstein JN, Johnston C, Gelein R, Cox C, Baggs R, Elder AC: Acute pulmonary effects of ultrafine particles in rats and mice. Res Rep Health Eff Inst 2000, 96:5-74. disc 75-86.

28. Bakand S, Hayes A, Dechsakulthorn F: Nanoparticles: a review of particle toxicology following inhalation exposure. Inhal Toxicol 2012, 24:125-135.

29. Muhlfeld C, Gehr P, Rothen-Rutishauser B: Translocation and cellular entering mechanisms of nanoparticles in the respiratory tract. Swiss Med Wkly 2008, 138:387-391.

30. Geiser M, Casaulta M, Kupferschmid B, Schulz H, Semmler-Behnke M, Kreyling $\mathrm{W}$ : The role of macrophages in the clearance of inhaled ultrafine titanium dioxide particles. Am J Respir Cell Mol Biol 2008, 38:371-376.

31. Ma R, Levard C, Marinakos SM, Cheng Y, Liu J, Michel FM, Brown GE, Lowry GV: Size-controlled dissolution of organic-coated silver nanoparticles. Environ Sci Technol 2012, 46:752-759.

32. Leo BF, Chen S, Kyo Y, Herpoldt KL, Terrill NJ, Dunlop IE, McPhail DS, Shaffer MS, Schwander S, Gow A, Zhang J, Chung KF, Tetley TD, Porter AE, Ryan MP: The stability of silver nanoparticles in a model of pulmonary surfactant. Environ Sci Technol 2013, 47:11232-11240.

33. Stebounova LV, Guio E, Grassian VH: Silver nanoparticles in simulated biological media: a study of aggregation, sedimentation, and dissolution. J Nanopar Res 2011, 13:12.

34. Kent RD, Vikesland PJ: Controlled evaluation of silver nanoparticle dissolution using atomic force microscopy. Environ Sci Technol 2012, 46:6977-6984

35. Zook JM, Long SE, Cleveland D, Geronimo CL, MacCuspie Rl: Measuring silver nanoparticle dissolution in complex biological and environmental matrices using UV-visible absorbance. Anal Bioanal Chem 2011, 401:1993-2002.

36. Pratsinis A, Hervella P, Leroux JC, Pratsinis SE, Sotiriou GA: Toxicity of silver nanoparticles in macrophages. Small 2013, 9:2576-2584.

37. Beer C, Foldbjerg R, Hayashi Y, Sutherland DS, Autrup H: Toxicity of silver nanoparticles - nanoparticle or silver ion? Toxicol Lett 2012, 208:286-292.

38. Wang $X$, Ji Z, Chang CH, Zhang H, Wang M, Liao YP, Lin S, Meng H, Li R, Sun B, Winkle LV, Pinkerton KE, Zink JI, Xia T, Nel AE: Use of coated silver nanoparticles to understand the relationship of particle dissolution and bioavailability to cell and lung toxicological potential. Small 2014, 10:385-398.

39. Singh S, Kumar A, Karakoti A, Seal S, Self WT: Unveiling the mechanism of uptake and sub-cellular distribution of cerium oxide nanoparticles. $\mathrm{Mol}$ Biosyst 2010, 6:1813-1820.

40. Herzog F, Clift MJ, Piccapietra F, Behra R, Schmid O, Petri-Fink A, Rothen-Rutishauser B: Exposure of silver-nanoparticles and silver-ions to lung cells in vitro at the air-liquid interface. Part Fibre Toxicol 2013, 10:11.

41. Lubick N: Nanosilver toxicity: ions, nanoparticles-or both? Environ Sci Technol 2008, 42:8617.

42. Park EJ, Yi J, Kim Y, Choi K, Park K: Silver nanoparticles induce cytotoxicity by a Trojan-horse type mechanism. Toxicol In Vitro 2010, 24:872-878.

43. Limbach LK, Wick P, Manser P, Grass RN, Bruinink A, Stark WJ: Exposure of engineered nanoparticles to human lung epithelial cells: influence of chemical composition and catalytic activity on oxidative stress. Environ Sci Technol 2007, 41:4158-4163.

44. Stoeger T, Reinhard C, Takenaka S, Schroeppel A, Karg E, Ritter B, Heyder J, Schulz H: Instillation of six different ultrafine carbon particles indicates a surface area threshold dose for acute lung inflammation in mice. Environ Health Perspect 2006, 114:328-333.

45. Horie M, Fukui H, Endoh S, Maru J, Miyauchi A, Shichiri M, Fujita K, Niki E, Hagihara $\mathrm{Y}$, Yoshida $\mathrm{Y}$, Morimoto $\mathrm{Y}$, Iwahashi $\mathrm{H}$ : Comparison of acute oxidative stress on rat lung induced by nano and fine-scale, soluble and insoluble metal oxide particles: $\mathrm{NiO}$ and TiO2. Inhal Toxicol 2012, 24:391-400.

46. Duffin R, Tran L, Brown D, Stone V, Donaldson K: Proinflammogenic effects of low-toxicity and metal nanoparticles in vivo and in vitro: highlighting the role of particle surface area and surface reactivity. Inhal Toxicol 2007, 19:849-856.

47. Kobayashi N, Naya M, Endoh S, Maru J, Yamamoto K, Nakanishi J: Comparative pulmonary toxicity study of nano-TiO(2) particles of different sizes and agglomerations in rats: different short- and long-term post-instillation results. Toxicology 2009, 264:110-118.

48. Ho M, Wu KY, Chein HM, Chen LC, Cheng TJ: Pulmonary toxicity of inhaled nanoscale and fine zinc oxide particles: mass and surface area as an exposure metric. Inhal Toxicol 2011, 23:947-956.
49. Zhu MT, Feng WY, Wang B, Wang TC, Gu YQ, Wang M, Wang $Y$, Ouyang $H$, Zhao YL, Chai ZF: Comparative study of pulmonary responses to nano- and submicron-sized ferric oxide in rats. Toxicology 2008, 247:102-111.

50. Pauluhn J: Pulmonary toxicity and fate of agglomerated 10 and $40 \mathrm{~nm}$ aluminum oxyhydroxides following 4-week inhalation exposure of rats: toxic effects are determined by agglomerated, not primary particle size. Toxicol Sci 2009, 109:152-167.

51. Roursgaard M, Poulsen SS, Poulsen LK, Hammer M, Jensen KA, Utsunomiya S, Ewing RC, Balic-Zunic T, Nielsen GD, Larsen ST: Time-response relationship of nano and micro particle induced lung inflammation. Quartz as reference compound. Hum Exp Toxicol 2010, 29:915-933.

52. Gosens I, Mathijssen LE, Bokkers BG, Muijser H, Cassee FR: Comparative hazard identification of nano- and micro-sized cerium oxide particles based on 28-day inhalation studies in rats. Nanotoxicology 2013, 8:643-653.

53. Krystek P, Braakhuis HM, Park MVDZ, Jong WH: Inductively Coupled Plasma-Mass Spectrometry in Biodistribution Studies of (Engineered) Nanoparticles. In Encyclopedia of Analytical Chemistry. John Wiley \& Sons, Ltd; 2013.

54. Krystek P: A review on approaches to biodistribution studies about gold and silver engineered nanoparticles by inductively couples plasma mass spectrometry. Microchem J 2012, 105:39-43.

\section{doi:10.1186/s12989-014-0049-1}

Cite this article as: Braakhuis et al:: Particle size dependent deposition and pulmonary inflammation after short-term inhalation of silver nanoparticles. Particle and Fibre Toxicology 2014 11:49.

\section{Submit your next manuscript to BioMed Central and take full advantage of:}

- Convenient online submission

- Thorough peer review

- No space constraints or color figure charges

- Immediate publication on acceptance

- Inclusion in PubMed, CAS, Scopus and Google Scholar

- Research which is freely available for redistribution 